\title{
Wind-induced internal seiches in Vossoroca reservoir, PR, Brazil
}

\section{Ondas Internas produzidas pelo vento no Reservatório do Vossoroca, PR, Brasil}

\author{
Rafael de Carvalho Bueno ${ }^{1}$ and Tobias Bernward Bleninger ${ }^{1}$ \\ ${ }^{1}$ Universidade Federal do Paraná, Curitiba, PR, Brasil \\ E-mails: rafael.bueno.itt@gmail.com (RCB), bleninger@ufpr.br (TBB)
}

Received: December 26, 2017 - Revised: March 08, 2017 - Accepted: April 25, 2018

\begin{abstract}
The vertical movements caused by internal waves in lakes and reservoirs have chemical and biological consequences for these ecosystems. The vast majority of studies that investigate internal waves are conducted on large lakes. There are just few researches that investigate this phenomenon on dendritic reservoirs. The purpose of this research was to identify internal waves (baroclinic mode) in the Vossoroca reservoir by using temperature time series recorded between May to November 2012. A two-layer method was used which considered rigid upper and lower boundaries. Moreover, the potential flow theory was used for both layers since the flow within each layer was considered irrotational. From the dispersion relation, we obtained the theoretical shallow internal wave period. The power spectral density (PSD) of temperature series of thermocline depth, provided by fast Fourier transform, helped in the identification on the frequency peak. Subsequently, the theoretical period was compared with the frequency spectra. Using a careful analysis (excluding the interference of solar radiation and intensity of wind), we observed a clear peak in November due to an internal wave with period around 8 hours, which matched the theoretical calculation from the dispersion relation equation for V1H1 mode. Weak winds from southwest excited a V1H1 baroclinic mode. According to spectral analysis, after the passage of this long-basin internal seiches, we identified the formation of higher vertical internal seiche modes. In addition, we observe indications of V1H1 mode degeneration.
\end{abstract}

Keywords: Internal seiches; Two-layer method modeling.

\section{RESUMO}

Os transportes verticais de nutrientes, compostos químicos e microrganismos causados pela presença de ondas internas causam um grande efeito no estado trófico de reservatórios. Poucas pesquisas buscam verificar a ocorrência de ondas internas em reservatórios, sistemas muitas vezes mais dendrítico que lagos. O objetivo desta pesquisa foi identificar ondas internas no reservatório do Vosorroca (Paraná), utilizando, para isso, séries de temperatura da coluna de água coletados entre os meses de Agosto e Novembro de 2012. Foi utilizado o método de duas camadas para a identificação da periodicidade das ondas internas. Através da relação de dispersão foram obtidos os períodos teóricos das ondas internas em águas rasas. As densidades espectrais de potência da série de temperatura na profundidade média da termoclina auxiliaram na identificação dos picos de frequências. Foi possível observar um grande pico de frequência durante o mês de Novembro, mês que apresentou maior estratificação térmica. O pico identificado como uma onda interna de periodicidade de 8 horas condiz com o período teórico de uma onda V1H1, obtido a partir do modelo. Ventos de baixa intensidade $(\approx 1 \mathrm{~m} / \mathrm{s})$ predominantemente direcionados à nordeste excitaram uma onda V1H1. De acordo com os espectros de potência, após a passagem desta onda foram verificadas ondas internas de modos baroclínicos superiores e uma possível degeneração da onda interna de periodicidade de $8 \mathrm{~h}$.

Palavras-chave: Seicha interna; Método das duas camadas. 


\section{INTRODUCTION}

The study of water movement in reservoirs gives us the understanding of physical, chemical and biological processes that occur in surfaces waters. According to Wetzel (2001), heat and dissolved substances can be transported by the water movements, and consequently the water body productivity may be dramatically altered. The vertical movements in lakes and reservoirs have chemical and biological consequences for these ecosystems (STRASKRABA; TUNDISI; DUNCAN, 2013). There are a huge number of events that are responsible for water movements on reservoirs and lakes. However, as stated by Denny and Gaines (2007), internal waves are one of the most important water movements for vertical mixing on lakes and reservoirs.

According to Downing et al. (2006), the internal motions of small lentic water bodies are poorly studied compared to large lakes. Generally, projects are used to investigate large lakes since they apparently have higher socioeconomic impact. However, Pannard et al. (2011) showed that, although internal waves in small lakes have seldom been investigated, small lentic water bodies present higher baroclinic pressure, which allows the formation of large internal waves. In addition, there have been relatively few serious research efforts on dendritic reservoirs, water basins with high shoreline development index, $L_{d}$. The shoreline development index is given by the ratio of the length of lakeshore to the circumference of a circle of equal area to the basin, which characterizes the irregularity of the lakeshore. The $L_{d}$ value grows as the shape of the surface basin deviates from a perfect circle. The large majority of basins that have been investigated to detect internal wave activity had $L_{d}<2.5$.

Internal waves are a kind of waves that propagate within a stratified fluid when it has been excited by an instability force (BENGTSSON; HERSCHY, 2012). In aquatic ecosystems the identification of these waves is common, mainly because those water bodies are frequently stratified environments, with exception of rivers, which have high instability frequency maintaining the system completely unstratified. On aquatic ecosystems, internal waves can be excited by innumerous instabilities forces, for example, gravity currents and intrusions, turbulence, diffusion and interaction between surface waves and bathymetry of the stratified basins. However, according to Mortimer (1952) in lakes and reservoirs, internal waves are commonly generated by wind action on the water surface.

Wind introduces kinetic energy at the water surface. The transfer of momentum caused by wind stress pushes the surface water to the leeward shore, causing a surface displacement, called as wind set-up. If the wind stress is acting over sufficient time periods, the horizontal pressure gradient increases, and the hypolimnion water is accelerated toward the upwind end. Consequently, the hypolimnion and epilimnion layer is tilted. When the wind stops, the tilted layers flow back towards equilibrium. However, momentum is considerable and equilibrium is overshot, resulting in a rocking motion about nodal points for long periods. Roget et al. (2017) identified internal waves in the changing South Aral Sea that has approximately $200 \mathrm{~km}$ of extension. Wind events of $3 \mathrm{~m} / \mathrm{s}$ lasting for 5 days were responsible to excite baroclinic motions. Bernhardt and Kirillin (2013) detected formation of internal waves during wind events between 3 and $5 \mathrm{~m} / \mathrm{s}$ in a long $(3.2 \mathrm{~km})$ lake, Arendsee Lake (Germany).

Although internal waves in a continuous stratified fluid travels horizontally along isopycnals and vertically along the density gradient, internal seiches frequently present more energy in specific depths. According to Münnich, Wüest and Imboden (1992), standing internal waves in closed basins may be classified by nodal points on the vertical $(\mathrm{V})$ and horizontal $(\mathrm{H})$ components. Thus, internal seiches are divided by these components, $\mathrm{V}_{n} \mathrm{H}_{m}$, in which $n$ and $m$ are the number of nodes of each component. Because of the high density difference, Mortimer (1952) showed that many times the energy concentrates near the thermocline, resulting in a two layer system, similar to Figure 1a. As Simmons et al. (2011) stated, the two-layer model is particularly useful to detect the first vertical internal wave mode, V1H1. Nonetheless, sometimes internal wave energy may be concentrated in different depths. The second vertical baroclinic mode (V2) normally presents more energy at both the top and bottom of the metalimnion, Figure 1b. According to Roget et al. (1997), the second vertical mode is more evidenced in small lakes where the metalimnion takes up a large proportion of the total depth. Moreover, the second baroclinic mode may also be associated with a more heterogeneous epilimnion.

Although the first two vertical modes are frequently excited in lakes and reservoirs, higher vertical modes have lower probability to be generated. Lazerte (1980) showed evidences of the formation of the sixth vertical baroclinic mode in Lake Frain, Michigan. As evidenced by Roget et al. (1997), Lazerte (1980) also concluded that higher vertical modes may be generated due to a diffuse metalimnion.

In spite of the fact that internal waves in lentic water bodies have been observed since Watson (1903), this phenomenon was investigated in details just by Mortimer (1952). Clifford Mortimer explored the formation of large standing internal waves, also called

\section{a) V1H1}

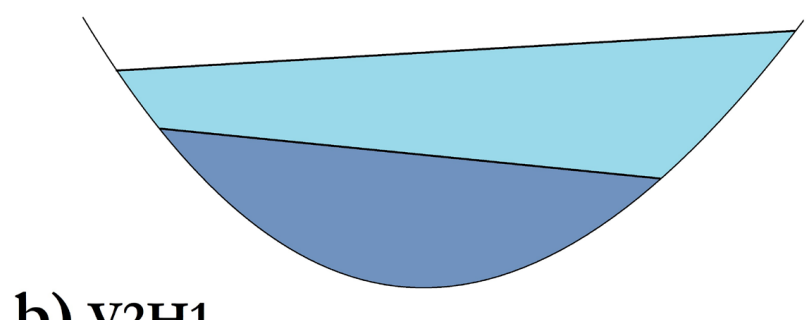

b) V2H1

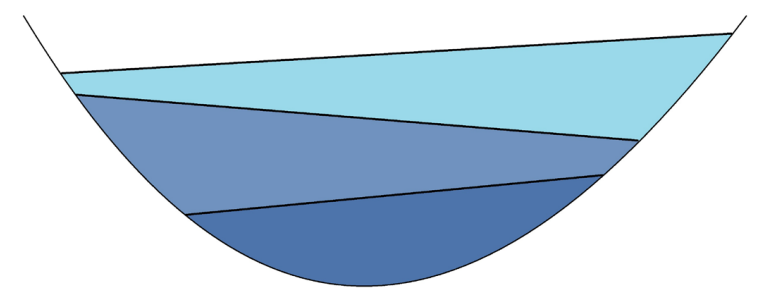

Figure 1. Schematic structure of standing internal waves of the first horizontal mode (H1). (a) first vertical mode (V1) and (b) second vertical mode (V2). 
internal seiches. Using a thermistor chain, he studied the generation of internal seiches due to wind events in Lake Windermere.

Even before the spectral analysis technique development, Mortimer (1952) concluded that the wind action over stratified lakes is responsible to generate long fundamental internal seiches, $\mathrm{V}_{n} \mathrm{H} 1$. Many studies have been conducted in lakes with $L_{d}<2.5$, in which highlighted studies handled in Lake Kinneret (ANTENUCCI; IMBERGER; SAGGIO, 2000), Lake Michigan (MORTIMER, 2004) and Lake Geneva (LEMMIN; MORTIMER; BÄUERLE, 2005). However, a small number of studies have investigated long internal seiches in small and dendritic stratified closed basins, with $L_{d} \gg 2.5$.

This research presents the first study about internal waves in Vossoroca reservoir. The Vossoroca reservoir ( $25^{\circ} 49^{\prime} 31^{\prime \prime} \mathrm{S}$, $49^{\circ} 03^{\prime} 60^{\prime} \mathrm{W}$ ) is a small and dendritic-shaped reservoir located $60 \mathrm{~km}$ from Curitiba, capital of Paraná State. The reservoir has a well-defined dendritic shape with $L_{d} \approx 4$. Thus, the purpose of this research is to investigate the formation of internal waves in small and dendritic-shaped stratified closed basins. To achieve the goals, we used water temperature measurements and meteorological data, solar radiation and wind speed, to identify internal waves. The data used was obtained during the second semester of 2012. We used to detect the baroclinic motion in this reservoir using a two-layered internal wave model and the spectral analysis of temperature series of thermocline depth, solar radiation, and wind speed.

\section{METHODS}

In this section we present all techniques used in this research to identify internal waves in Vossoroca reservoir-PR. Water temperature, solar radiation, and wind speed and direction were used to analyze the formation and structure of internal waves. The theoretical period of internal waves was obtained through water temperature and wind direction series. The system was divided into two layers, epilimnion and hypolimnion. Then, the mean theoretical period for each interval was calculated.

The theoretical period was compared with the power spectral densities (PSD) and the power spectrums (PS) to identify energetic peaks on the spectra that could be correlated to baroclinic activity. The solar radiation and wind intensity series were also applied to Fourier transforms. The technique was used to compare the water temperature spectrum with meteorological spectrum. The comparison was used to detect if some thermal fluctuation could be correlated to some meteorological fluctuation, helping to understanding the source of the thermal fluctuation. For example, the solar radiation spectrum may show the influence of energy on diurnal temperature fluctuations. This provides the understanding that sometimes the thermal fluctuation is not necessarily a physical wave, but a temporal thermal variation caused by the diurnal peak of solar radiation and their resonates peaks.

Although higher baroclinic modes have been linked to thermal stratification structure, the correlation between the spectrum of the wind velocity and thermal fluctuations, as observed by Münnich, Wüest and Imboden (1992), is an important indicator of higher baroclinic mode generation.

Figure 2 shows a schematic of how the method was applied in this research.

\section{Site description}

Vossoroca reservoir (2549' 31' S, 4903' 60” O), Figure 3, is located between Tijucas do Sul and São José dos Pinhais, $60 \mathrm{~km}$ from Curitiba, capital of Paraná State. The reservoir was built

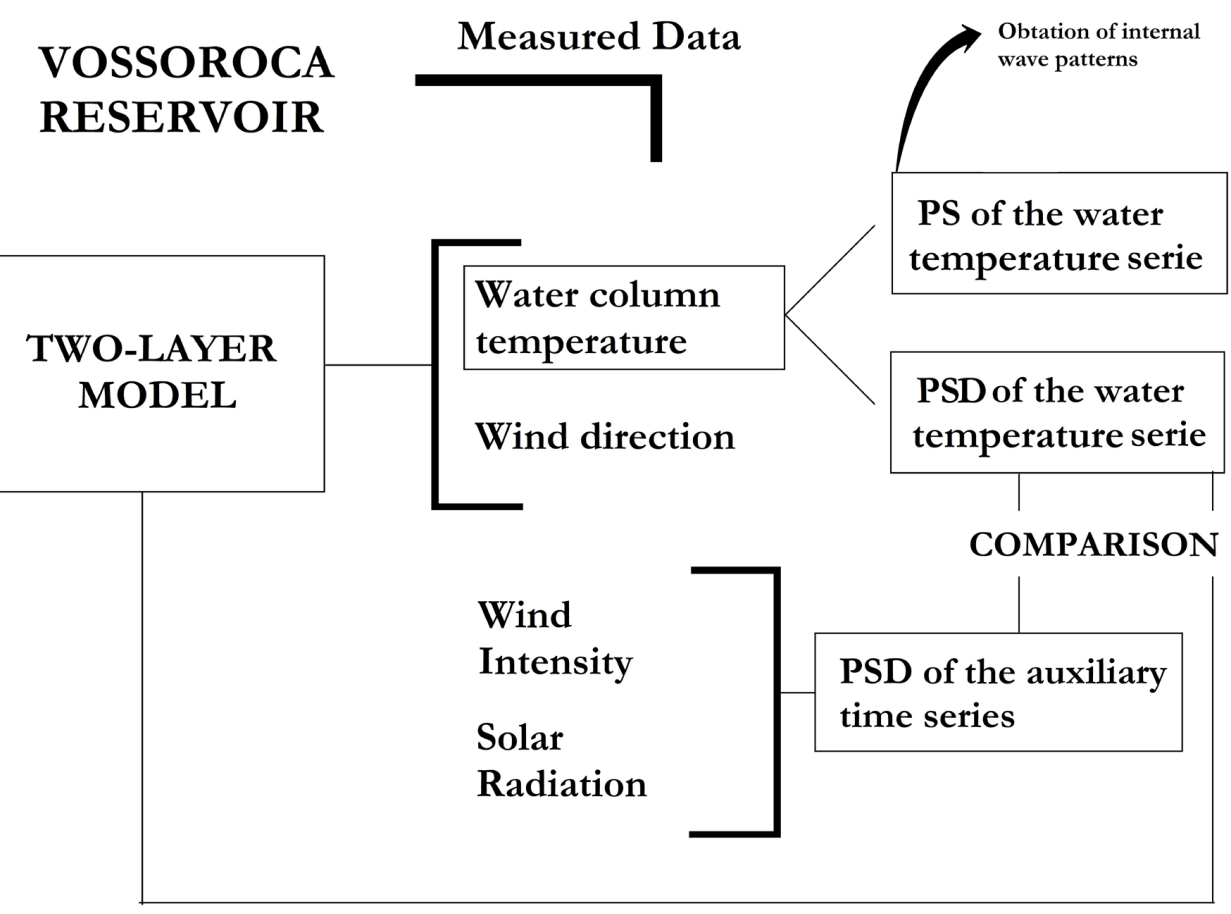

Figure 2. Schematic of technique to detect internal waves. 


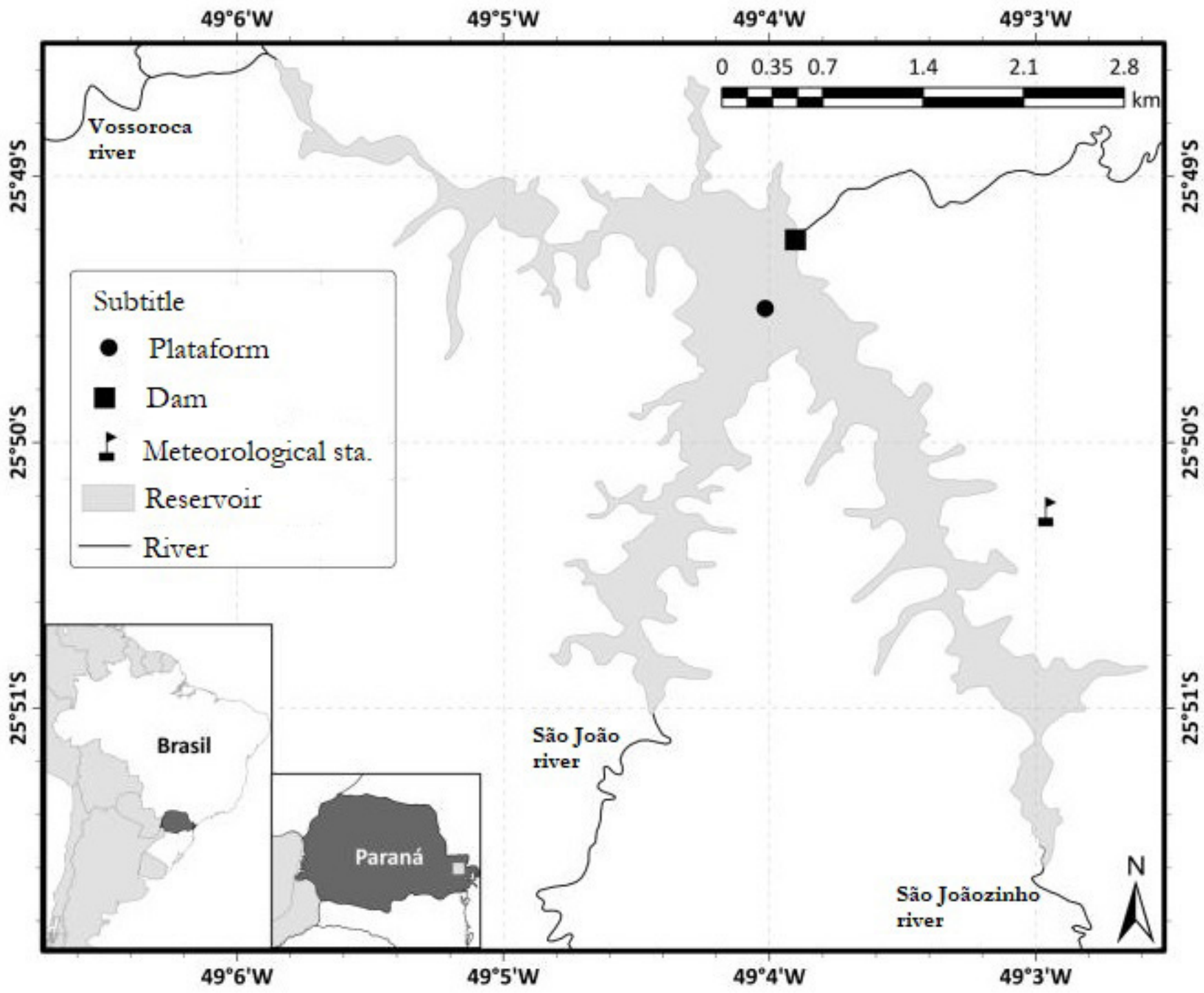

Figure 3. Map of Vossoroca reservoir.

in the end of the 1940s and is used to regulate the water flow that goes to Salto do Meio reservoir. The reservoir has an area of $330 \mathrm{ha}$, a volume of $35.710^{6} \mathrm{~m}^{3}$, a maximum depth of $17 \mathrm{~m}$, and an average depth of approximately $6 \mathrm{~m}$ (MANNICH, 2013).

The reservoir presents a shoreline development index of 4.2 and has two long narrow arms $300 \mathrm{~m}$ wide. The study site is located in a humid subtropical climate $(\mathrm{Cfb})$, presenting hot and humid summers with frequent frosts. The region presents effective mean annual precipitation of $1600 \mathrm{~mm}$ and mean annual temperature of approximately $17^{\circ} \mathrm{C}$ (WERNER, 2013).

Due to the topographical relief, the wind action over the reservoir is dominated essentially by northeasterly wind. The vertical temperature structure of Vossoroca reservoir correspond to holomictic lakes, presenting thermal stratification for nine months and during the winter an uniform temperature from top to bottom. Mixing periods start after April, but the system is completely unstratified only at the end of May. Around September, with the increase of solar radiation, a gentle stratification develops and, consequently, the reservoir starts to become stratified. During the summer, the temperature difference between epilimnion and hypolimnion reaches approximately $10{ }^{\circ} \mathrm{C}$.

Figure 3 shows the map of Vossoroca reservoir, indicating the location of the meteorological station, the dam, and the thermistor chain, where water temperature profiles were obtained.

\section{Temperature and meteorological data}

Meteorological data, solar radiation and wind intensity and direction, was used to characterize water temperature variations and the fundamental internal seiche wavelength. Wind direction and intensity were measured by a Young wind monitor with accuracy of $\pm 2^{\circ} \mathrm{e} \pm 0.3 \mathrm{~m} / \mathrm{s}$, respectively. Solar radiation was obtained by a Campbell Scientific CMP3-L Pyranometer with accuracy of $\pm 1 \mathrm{~W} / \mathrm{m}^{2}$. Both sensors were deployed in a meteorological platform in the basin shore, $2.5 \mathrm{~km}$ from the dam and $10 \mathrm{~m}$ above the reservoir lake, Figure 3. All information was obtained between August and November, 06/08/2012 - 24/11/2012. 
Internal waves were detected through thermal variation in the water column. Profiles of water temperature were acquired through a thermistor chain deployed at the north portion of the reservoir, in the deepest point, Figure 3. According to Mannich (2013), the chain position was chosen based on the location of highest temperature gradient during different seasons of the year. The chain was equipped with seven thermistors LM 35 with accuracy of $\pm 0.1^{\circ} \mathrm{C}$ and temperature range of 10 to $55^{\circ} \mathrm{C}$. Six thermistors were placed at water depths of $1 \mathrm{~m}, 3 \mathrm{~m}, 5 \mathrm{~m}, 7 \mathrm{~m}, 9 \mathrm{~m}$, and $11 \mathrm{~m}$. The seventh sensor was fixed $1 \mathrm{~m}$ above the bottom of the reservoir, in a reference depth of $799 \mathrm{~m}$. All thermistors were adjusted to recover temperature values every 15 minutes. The data was obtained between August and November, same period that we obtained the wind and solar radiation information.

Figure 4 shows a schematic configuration of the thermistor chain deployed in Vossoroca reservoir. A comprehensive summary of the assembly and installation procedure of all devices used in this research is given by Mannich (2013).

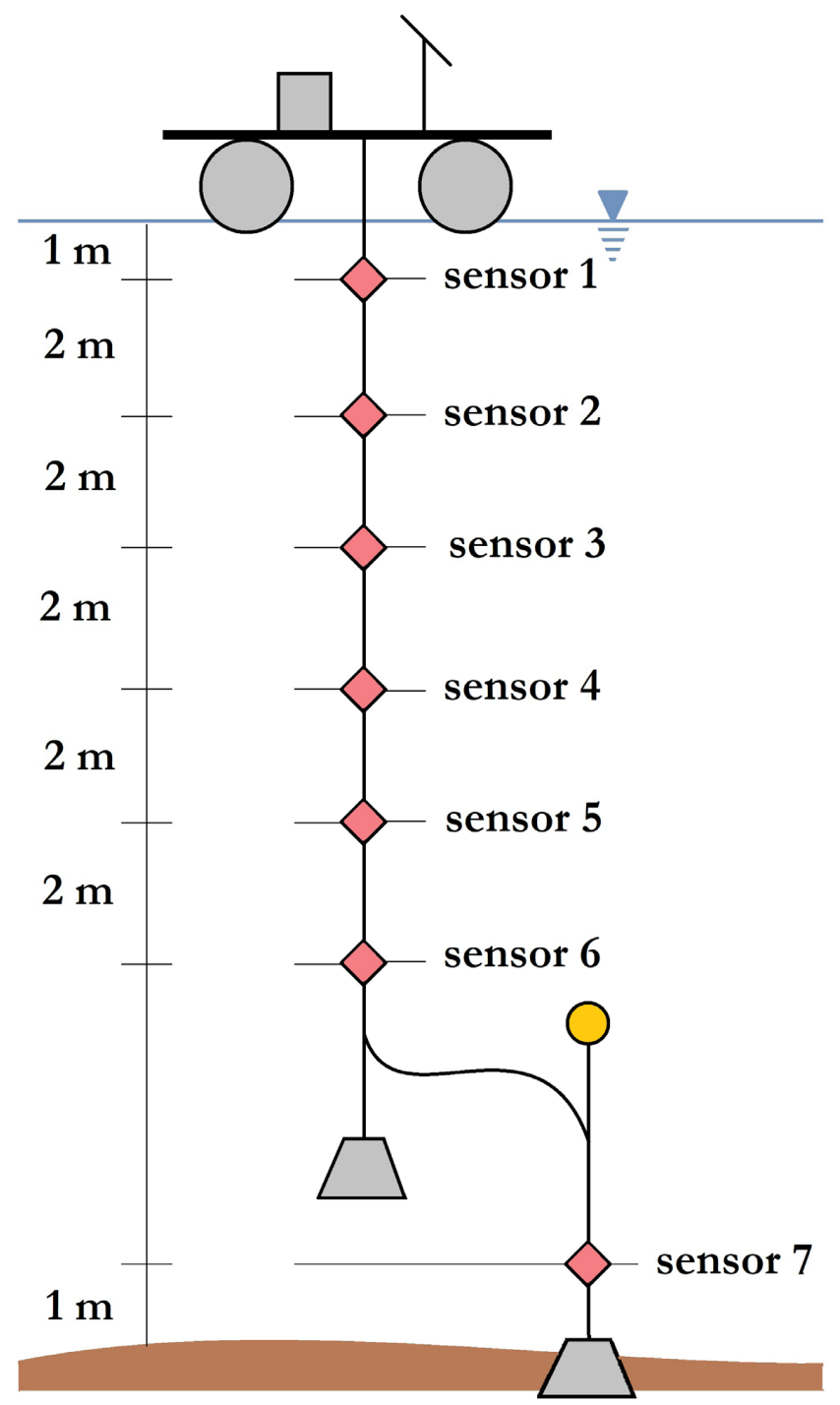

Figure 4. Schematic configuration of the thermistor chain deployed in Vossoroca reservoir.
We adjusted the values of temperature according to the water level that was obtained through a limnimeter deployed at basin shore. The limnimeter used in this study recovered water level every 30 minutes.

\section{Preprocessing of temperature data.}

We validated the temperature profiles obtained by the thermistor chain with a CTD device (Conductivity, Temperature, and Depth) in sporadic campaigns, once or twice a month from August to November 2012. We firstly interpolated linearly temperature profiles in a grid of $1 \mathrm{~mm}$ to obtain a higher grid in temperature scale, and consequently detected the mean thermocline depth. An adjustment was made in temperature values due to the water level change. When the water level reached a low value, and consequently one or more temperature sensors were below of the seventh thermistor, these sensors were neglected for the linear interpolations.

Even though many dissolved substances affect the thermodynamic properties of water in lakes and reservoirs, the large majority of studies neglect the effect of these substances in the change of water density since the temperature contribution is much higher in closed basins of fresh water. Bernhardt and Kirillin (2013) used these same hypotheses to identify internal waves in fresh water lake. According to Bernhardt and Kirillin (op. cit.), the temperature is the only variable that affects the internal wave propagation in this kind of ecosystems. Thus, we calculated water density profiles based on temperature only since the system is only thermal stratified. To obtain water density values we used the equation of state proposed by Fofonoff and Millard (1983).

Thus, we neglected the contribution of pressure to water density since we considered the hypotheses of incompressible flow. In addition, we neglected the contribution of salinity to density since the temperature contribution is much higher in reservoirs of fresh water (WILDERER, 2010). This procedure was similar done by Bernhardt and Kirillin (2013).

\section{The two-layer model}

Motivated by his observations in Lake Windermere in 1903 (WATSON, 1903), Watson (1904) developed the first model to predict internal seiche patterns in closed basins. Watson (1904) used in his model the hydrostatic approximation and the shallow water assumption, valid when $L \gg H$, where L: horizontal scales, and $\mathrm{H}$ the dominant vertical scales. The model considers a rectangular closed basin divided into two layers of homogeneous density. Mortimer (1952) tested the Watson's model for the same Lake Windermere and observed a good agreement with the observed periods; presenting errors lower than 5\%. Pannard et al. (2011) also used an analytical representation to describe the evolution of internal waves. He applied the analytical model to Lake Bromont (Quebec, Canada) and obtained error lower than $12 \%$ for mode $\mathrm{V} 1 \mathrm{H} 1$. The vast majority of internal wave studies present difference of modeled and observed wave periods greater than $5 \%$ and lower than $20 \%$. As a consequence the two-layer approximations often can be applied. Thus, considering a basin with a well-defined 
thermocline and high water stratification, we can often reduce the continuously stratified system into a system composed just by two layers.

Although this approximation can be frequently applied in lakes and reservoirs with high thermal stratification, density gradients in nature are always continuous. Thus, as stated by Hutter, Wang and Chubarenko (2011), in real cases, the energy may concentrate in different depths of the system, exciting higher baroclinic modes. The difficulty to work with a continuously stratified fluid and complex geometry system arises due to the complexity to find an analytical solution for momentum and mass conservation equations. Since the water density varies continuously with depth, we cannot make the irrotational flow assu mptions, and consequently we cannot define a velocity potential. In addition, another problem arises in breaking events of internal waves, where complicated anisotropic turbulence features need to be solved.

The dispersion relation solution can be easily obtained analytically for a simplified two-layer system and linear internal waves. As our aim is not to obtain a quantitative description of the action of nonlinear internal waves and its degeneration, the usage of this technique is useful to identify long internal waves with linear trend.

We used in this research a non-hydrostatic unidimensional linear internal wave model based on models developed by Watson (1904) and Mortimer (1952). However, differently to Watson's model (WATSON, 1904), we did not apply the hydrostatic approximation in our application. Considering a system of just two homogeneous layers, Figure 5, the only region where there is a discontinuity on the water density is on the interface between epilimnion and hypolimnion. Then, within each layer we applied the irrotational assumption, and consequently we could define independent velocity potentials for each layer.

We also applied other simplifications in the model. The fluids are considered immiscible and the flows of both layers are considered incompressible. Moreover, the flows are inviscid and the Coriolis force is neglected. In addition, the flow occurs essentially in two dimensions. According to the simplifications introduced previously, the mass conservation equation can be written as the Laplace equation for each layer, Equation 1. The momentum equations for each layer can be reduced to the unsteady Bernoulli equations, Equation 2, due to the simplifications imposed to the model.

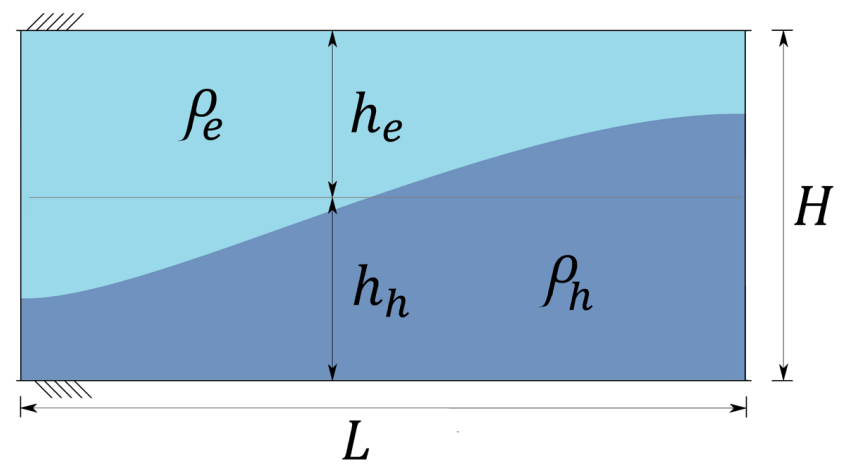

Figure 5. Schematic view of a two-layer system with homogenous layers.

$$
\begin{aligned}
& \frac{\partial^{2} \phi_{l}}{\partial x^{2}}+\frac{\partial^{2} \phi_{l}}{\partial z^{2}}=0 \\
& \frac{\partial \phi_{l}}{\partial t}+\frac{P}{\rho_{l}}+g z=f(t)
\end{aligned}
$$

in which $\phi_{l}$ is the velocity potential of layer $l, \rho_{l}$ is the mean water density of layer $l, P$ is the total thermodynamic pressure, and $g$ is the acceleration due to gravity.

According to Kodaira et al. (2016), surface perturbation in lakes and reservoirs is often negligible, and consequently the rigid lid approximation is valid. Thus, as our goal is the identification of baroclinic motions, the water-air perturbation can be neglected, Figure 5. This is also analog to the bottom of the basin, in which we can apply the rigid lid approximation since the water does not disturb the sediment.

At the interface there are four linearized boundary conditions, two kinematic conditions and two dynamic conditions. The kinematic conditions describe the vertical displacement and velocity of the interface disturbance. The dynamic condition is obtained through Equation 2 for each layer. These conditions are responsible to describe the evolution of the water level, representing the internal wave evolution.

Thus, the velocity potential of each layer and the interfaces disturbance satisfy all linearized boundary conditions, two kinematic conditions, two dynamic conditions, and two rigid boundary conditions.

Using the variable change technique and all boundary conditions mentioned before, we can find the Laplace solutions. The dispersion relation of interfacial waves was based on solution obtained by Socolofsky and Jirka (2005).

$$
\omega^{2}=\frac{g \pi m \Delta \rho}{L\left(\rho_{e} \operatorname{coth}\left(k h_{e}\right)+\rho_{h} \operatorname{coth}\left(k h_{h}\right)\right)}
$$

in which $\omega$ is the internal wave angular frequency, $L$ is the reservoir length aligned with the internal wave propagation in the thermocline depth, $h_{e}$ and $h_{h}$ are the epilimnion and hypolimnion thickness, respectively. $\rho_{e}$ and $\rho_{h}$ are the epilimnion and hypolimnion mean water density, respectively. In addition, $m$ is the $m$ th harmonic of an internal seiche, that describes the horizontal baroclinic modes $(\mathrm{Hm})$.

The dispersion relation, Equation 3, can be simplified considering a shallow water system $(L \gg H)$. This approximation has been used by Mortimer (1952). Thus, Equation 3 can be rewritten as

$$
\omega^{2}=\frac{g \pi^{2} m^{2} \Delta \rho h_{e} h_{h}}{L\left(\rho_{e} h_{h}+\rho_{h} h_{e}\right)} .
$$

Equation 4 is known as the dispersion relation for fundamental internal seiches $(\mathrm{V} 1 \mathrm{H} 1)$ in shallow water system and can be used for $\lambda / H \geq 4 \pi$, where $\lambda$ is the wavelength and $H$ is the total depth of the basin. Moreover, we can obtain more variables to describe the internal wave patterns using the polarization relations.

We divided the stratified closed basin into two well defined layers, epilimnion and hypolimnion, to obtain all important characteristic parameters. As we recorded temperature profiles using just seven thermistors 2 meter spaced, we found the thermocline using the approach proposed by Read et al. (2011). 
According to Read et al. (2011), this weighting scheme showed a significant improvement in accuracy compared to the simple approximation, which assumes that the thermocline is located in the middle of sensors that present the highest temperature difference. As Read et al. (2011) stated the technique presented a significant reduction of the average error, approximately $20 \%$ for 2 meters intervals.

Thus, we estimated thermocline depth within the region of highest density difference. Considering that the maximum density gradient is located between sensor $\tau$ and $\tau+1$, Figure 6, the thermocline depth can be estimated by Equation 5. Figure 6 presents the detailed scheme of the approach

$Z_{t}=Z_{\tau+1}\left(\frac{\Delta_{\rho+1}}{\Delta_{\rho-1}+\Delta_{\rho+1}}\right)+Z_{\tau}\left(\frac{\Delta_{\rho-1}}{\Delta_{\rho-1}+\Delta_{\rho+1}}\right)$

where:

$$
\Delta_{\rho+1}=\frac{Z_{\tau \Delta+1}-Z_{\tau \Delta}}{\left(\frac{\rho_{\tau+1}-\rho_{\tau}}{Z_{\tau}-Z_{\tau+1}}-\frac{\rho_{\tau+2}-\rho_{\tau+1}}{Z_{\tau+1}-Z_{\tau+2}}\right)}
$$

and

$$
\Delta_{\rho-1}=\frac{Z_{\tau \Delta}-Z_{\tau \Delta-1}}{\left(\frac{\rho_{\tau+1}-\rho_{\tau}}{Z_{\tau}-Z_{\tau+1}}-\frac{\rho_{\tau}-\rho_{\tau-1}}{Z_{\tau}-Z_{\tau-1}}\right)}
$$

Since this procedure proposed by Read et al. (2011) uses two thermistor data above and below the thermocline, the thermocline region could not be located between the first and last thermistors. Thus, when the thermocline was observed between the first and last sensors, the thermocline depth was calculated by the simple approximation that the thermocline is located in the midpoint depth between measurements $\tau$ and $\tau+1$, Equation 6 .

$Z_{t}=\frac{Z_{\tau}-Z_{\tau+1}}{2} \equiv Z_{\tau \Delta}$

This thermocline elevation was used to compute the thickness of each layer, using Equations 7 and 8.

$h_{e}=Z_{s}-Z_{t}$

$h_{h}=Z_{t}-Z_{l}$

in which $h_{e}$ is the epilimnion thickness, $h_{h}$ is the hypolimnion thickness, $Z_{s}$ is the surface elevation, $Z_{t}$ is the thermocline elevation, and $Z_{l}$ is the reference elevation, where we considered $800 \mathrm{~m}$ for the Vossoroca reservoir bottom. The mean water density of each layer was calculated through the simple arithmetic mean, as schematized in Figure 7.

The last characteristic parameter to determine the internal wave period is the reservoir length $L$ aligned with the internal wave propagation in the mean thermocline depth, $L$. Thus, the wind direction measurements were used to determine the wind fetch, and consequently the direction of the internal waves action. Note that $L$ is not the entire length between the surface shore, but the length of the intersection between the shoreline walls and the thermocline. Since the mean thermocline and mean wind direction vary along the period, the values varied for different periods.

We calculated the theoretical angular frequency and period of internal waves, that are susceptible to be generated considering the system characteristics, through Equation 4, the reservoir length $L$, and the thickness of each layer. Since we defined an equation to describe the generation of fundamental internal seiches mode and this mode is frequently dominant in lakes and reservoirs, we focused our attention to capture the occurrence of the first vertical baroclinic mode, $n=1$ (MORTIMER, 1971).

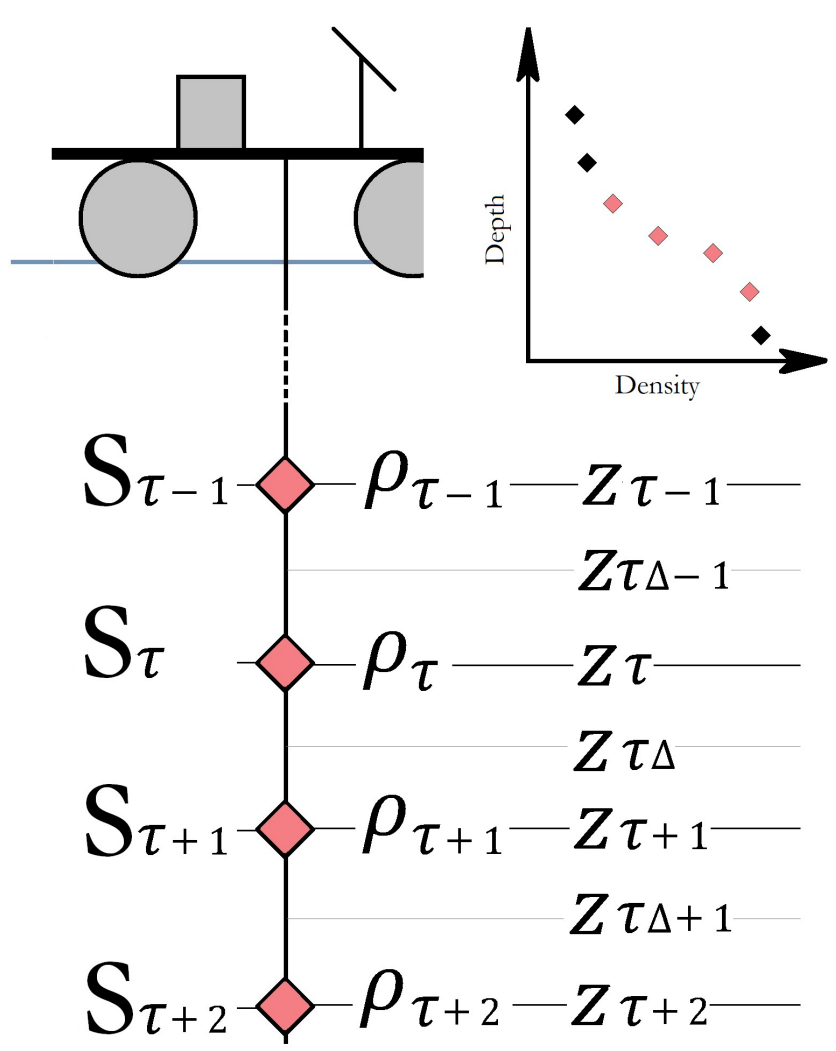

Figure 6. Weighting scheme to find the thermocline depth.

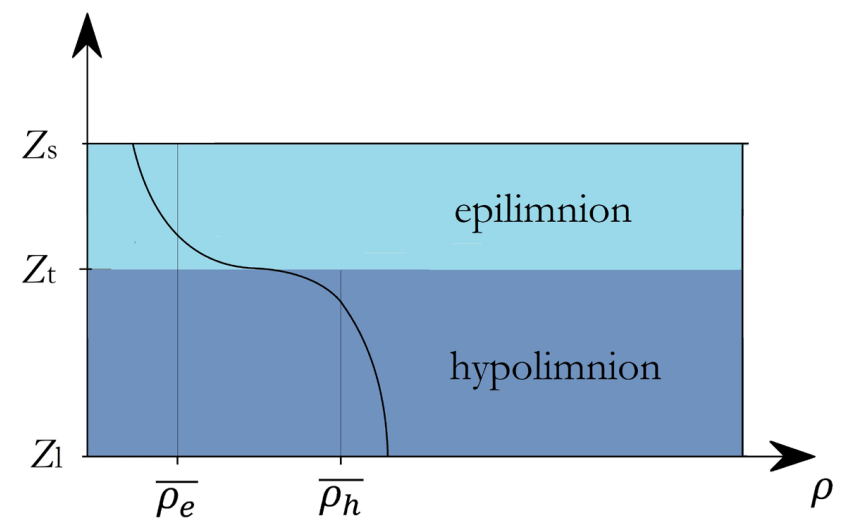

Figure 7. Two-layer model, in which $\bar{\rho}_{e}$ is the mean epilimnion water density and $\bar{\rho}_{h}$ is the mean hypolimnion water density. 
However, as observed by Hutter, Wang and Chubarenko (2011), small stratified closed basins are often susceptible to excite higher vertical baroclinic modes, which can be many times dominant in this type of system. Thus, we also investigated the existence of higher baroclinic motion, however, without a precise description of the type of the higher baroclinic mode found.

\section{Power Spectral Density and Power Spectrum (PSD / PS)}

To highlight the periodicity of thermal fluctuation within the stratified basin, we used a spectral analysis technique based essentially on Fourier transforms. We applied the Fourier transform and the power spectral density on thermal fluctuation data at the mean thermocline depth for a given period. As stated by Sutherland, 2016, since the energy generally concentrates near regions of high density differences, we chose to analyze the generation of internal waves at thermocline depth. However, as the thermocline varies with time, we took the mean thermocline of the analyzed period. The thermal oscillation spectrum was compared to the modeled results, which were obtained through the two-layer model. We tried to identify peaks in the energy spectrum in the same range of the frequency modeled by the two-layer model.

In addition, we compared the spectrum of the thermal fluctuation at the mean thermocline elevation with the spectrum of the meteorological data, obtained from wind intensity and solar radiation measurements. We performed spectral analysis for solar radiation fluctuation to remove the influence of sun energy on diurnal periods and its resonant events on thermal fluctuation data. Note that the fluctuation caused by solar radiation is not a physical wave but creates also a thermal fluctuation that needs to be detached from thermal oscillations due to internal wave activity. The comparison between the thermal spectrum and the wind velocity spectrum was done to analyze the existence of higher vertical modes. According to Munnich et al. (1992) wind oscillations at diurnal and inertial periods and their resonant events can strongly increase the intensity of baroclinic motion, exciting higher vertical modes.

As recommended by Havelock, Kuwano and Vorländer (2008), we normalized the fast Fourier transform and applied the following preprocessing techniques before to obtain the power spectral density of all relevant variables.

Firstly all data submitted to the Fourier analysis, which included water temperature and meteorological data, was smoothed by the smooth function from Scipy (2014). We also removed the linear trend of temperature values from the mean thermocline depth using the detrend function (SCIPY, 2016). This technique reduces the effect of the surface water elevation, which can modify the frequency spectrums.

Then, we applied the Fourier analysis to overlapping data segments using essentially the Hamming window function. The application of a windowed Fourier analysis helps to reduce the spectral leakage problem (PAPANDREOU-SUPPAPPOLA, 2002). Discontinuities involved when the Fourier transform is applied on time series often causes spectral leakage. The windowed Fourier analysis partitions the signal into several segments and multiplies each segment by a window function, a technique similarly to a convolution of the frequency spectrum. Moreover, we applied the overlapping process to increase frequency-resolution and the data loss. As recommended by Heizel and Rudiger (2002) for Hamming window function, we used $50 \%$ overlap percentage.

Another important value in the preprocessing procedure to apply the Fourier analysis is the NFFT, or also written as $\mathrm{N}_{\text {FFT }}$. The NFFT is the number of spectral estimates, the number of points used to generate each discrete Fourier transform spectrum. Thus, we divided the time series into several segments to reduce the difficulty to analyze non-stationary signals, reducing the variance of the energy spectrum. Finally, the last value defined before the application of the Fourier transforms was the data frequency, defined as FS. The FS is the frequency resolution of the discrete measurements. Thus, we used for water temperature signal a FS $=0.0011 \mathrm{~Hz}$ whilst to meteorological data a FS $=0.0083 \mathrm{~Hz}$.

\section{Analyzed periods}

The analysis of internal waves occurrence in Vossoroca reservoir was conducted through water temperature, surface water elevation and meteorological measurements, such as wind intensity and direction, done in the second semester of 2012. The whole period was divided into four groups, each one belonging to different months. Thus, we analyzed internal waves in August, September, October, and November. Table 1 shows a summary of all sub-periods analyzed.

The selection of periods was based on data quality and the values of the Brunt-Vaisalla frequency of each period. The Brunt-Vaisalla frequency was computed to evaluate the thermal stratification intensity and its time variation. Abrupt oscillations may indicate inconsistency failures of water temperature series or rapid changes on internal wave patterns, which may increase complexity to analyze the internal wave evolution. Thus, we selected periods with high Brunt-Vaisalla frequency, but which presented low standard deviation. Table 2 presents the mean direction of the wind and the reservoir length aligned with the internal wave propagation in the thermocline depth for each analyzed period.

Table 1. Analized periods.

\begin{tabular}{cc}
\hline GROUP & PERIODS \\
\hline A & $06 / 08 / 2012-17 / 08 / 2012$ \\
B & $10 / 09 / 2012-19 / 09 / 2012$ \\
C & $18 / 10 / 2012-27 / 10 / 2012$ \\
D & $16 / 11 / 2012-24 / 11 / 2012$ \\
\hline
\end{tabular}

Table 2. Mean wind direction and the closed basin length aligned with the internal wave action.

\begin{tabular}{ccc}
\hline GROUP & $\begin{array}{c}\text { WIND MEAN } \\
\text { DIRECTION }\end{array}$ & $\begin{array}{c}\boldsymbol{L} \\
\mathbf{( K m})\end{array}$ \\
\hline $\mathrm{A}$ & $123^{\circ}$ & 2.2 \\
$\mathrm{~B}$ & $141^{\circ}$ & 3.0 \\
$\mathrm{C}$ & $178^{\circ}$ & 1.2 \\
$\mathrm{D}$ & $117^{\circ}$ & 2.2 \\
\hline
\end{tabular}




\section{RESULTS AND DISCUSSION}

Table 3 shows the mean thermocline depth and the theoretical $1^{\text {st }}$ baroclinic mode period. The values were obtained through the characteristics parameters for each period.

The theoretical internal wave period was calculated using the thermocline elevation, mean water density for each layer and the reservoir length $L$ in the thermocline depth. We computed the mean internal seiche period averaging all the fetch vectors within \pm 20 degrees from the main wind direction. The reservoir length at the mean thermocline elevation was obtained through a linear interpolation of the wind direction and the basin length measurements, $L$. The reservoir length, $L$, for each wind direction was obtained through bathymetric graphs in intervals of $2^{\circ}$ from the northbound of the reservoir and each 3 meters depth.

The power spectral density of the temperature fluctuation in the mean thermocline depth for group A showed that the thermal fluctuation does not present energetic peaks that could not be correlated to meteorological data, Graph 1.

Thus, the $24 \mathrm{~h}$ and $12 \mathrm{~h}$ periodicity, observed on water temperature spectrum, are not necessarily due to an internal wave passage. The $12 \mathrm{~h}$ peak has low energy and follows a similar behavior as the resonant peaks of the diurnal solar radiation. As a result, the energetic peaks observed in Graph 1 represent the thermal oscillations due to the solar radiation, the peaks do not represent a physical wave.

The spectrum of the thermal fluctuations of group B has the same behavior observed in group $\mathrm{A}$, the temperature oscillation on the mean thermocline depth matches with spectrums of wind intensity and solar radiation. However, thermal variations in the $15 \mathrm{~h}$ periodicity present a slight change of behavior from meteorological spectrums, Graph 2.

The low correlation between water temperature and the low correlation between water temperature and meteorological series in periodicity of $15 \mathrm{~h}$ occurs due to the passage of an internal seiche. The $15 \mathrm{~h}$ periodicity does not match with the $\mathrm{V} 1 \mathrm{H} 1$ period calculated through the two-layer model, Table 3. These thermal fluctuations are also not correlated to higher horizontal baroclinic mode excitation since higher horizontal modes produce higher frequency waves, which essentially have lower periods than fundamental modes. Thus, $15 \mathrm{~h}$ periodicity of the excited internal seiche probably is a higher vertical internal seiche mode.

The power spectrum of the thermocline depth for group B corroborates to the assumption that there is an excitation of higher vertical baroclinic modes, Graph 3. The low energy observed in the thermocline depth and the great periodicity indicates that the internal wave energy probably is not located in the thermocline region, but in another depth. The internal wave exited in group B

Table 3. Mean thermocline depth and theoretical internal seiche period with the standard deviation for each group.

\begin{tabular}{ccc}
\hline GROUP & $\begin{array}{c}\text { THERMOCLINE } \\
\text { ELEV. }\end{array}$ & $\begin{array}{c}\text { THEORETICAL } \\
\text { PERIOD }\end{array}$ \\
\hline A & $810.26 \mathrm{~m}$ & $12 \mathrm{~h} 00 \pm 1 \mathrm{~h} 30$ \\
B & $808.50 \mathrm{~m}$ & $11 \mathrm{~h} 00 \pm 1 \mathrm{~h} 05$ \\
C & $806.71 \mathrm{~m}$ & $4 \mathrm{~h} 30 \pm 45 \mathrm{~min}$ \\
D & $806.96 \mathrm{~m}$ & $7 \mathrm{~h} 00 \pm 1 \mathrm{~h}$ \\
\hline
\end{tabular}

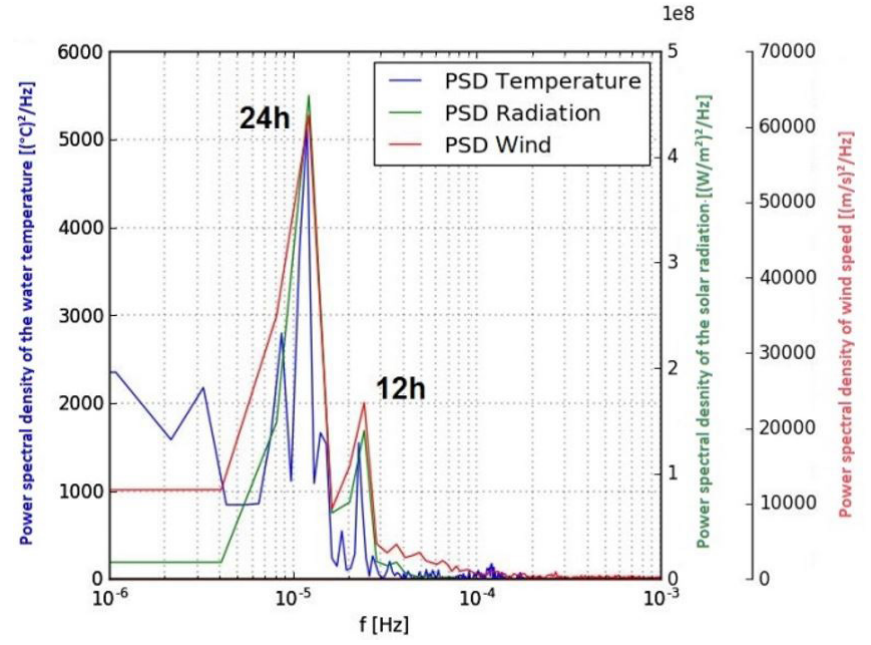

Graph 1. Power spectral density of the temperature and meteorological series for group A.

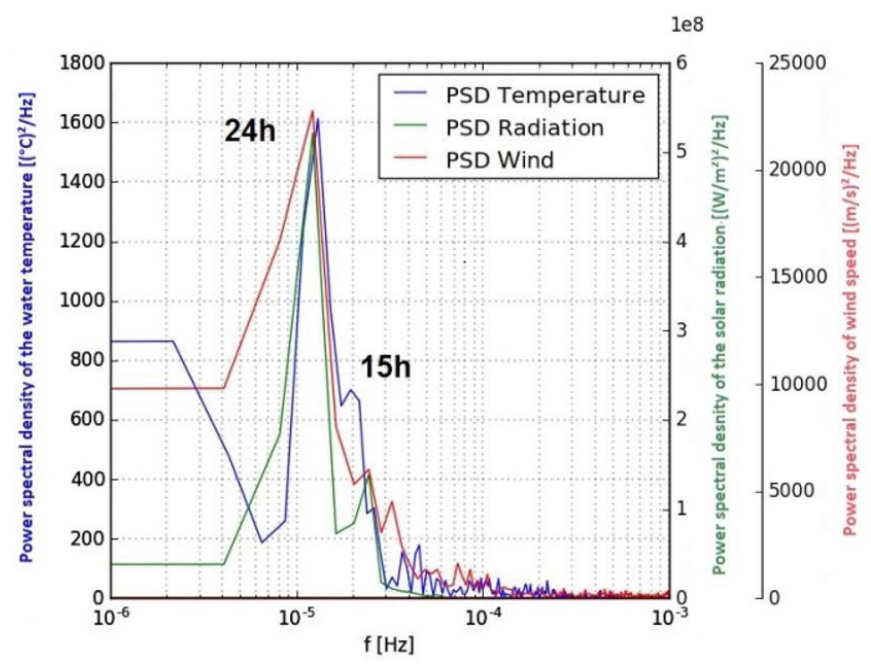

Graph 2. Power spectral density of the temperature and meteorological series for group B.

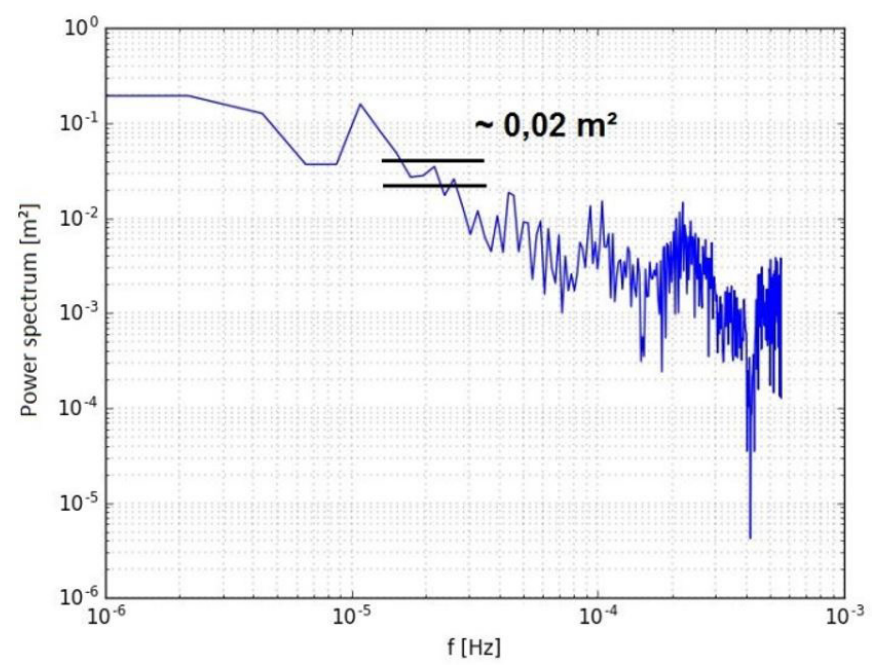

Graph 3. Power spectrum of the thermocline fluctuation for group B. 
has a periodicity equal to $15 \mathrm{~h}$ and causes a water displacement of $14 \mathrm{~cm}$, Graph 3.

Although internal waves have been excited during this period, the displacement is small, and consequently the internal seiche with a large period of $15 \mathrm{~h}$ does not present a notorious mixing effect in the reservoir. According to Likens (2010), high vertical modes have normally lower energy compared to fundamental internal wave mode, which carry more than $98 \%$ of internal wave energy.

The spectrum of temperature in the mean thermocline depth for group $\mathrm{C}$ shows high correlation with solar radiation and wind intensity spectrum. As observed in group A, the thermal fluctuation does not present any energetic peak that cannot be correlated directly with the meteorological series, wind speed and solar radiation signals. Thus, we can conclude that there is no evidence of internal wave activity between 18 and 27 October 2012, Graph 4.

The power spectral densities of period D shows the excitation of three predominant and energetic peaks, which are not correlated to wind speed and solar radiation fluctuations, Graph 5. According to the spectral analysis, we can conclude that during this period, energetic internal seiches have been generated. The multiple peaks, observed through the power spectral density, indicate that probably there is more than one period of internal wave propagation. Moreover, non-dominant baroclinic modes could be excited during the propagation of dominant internal waves.

Another clue to the excitation of internal waves during November can be observed through the presence of huge oscillations in the high frequency spectrum, Graph 5. As Saggio and Imberger (1998) stated, long internal waves can be degenerated into high frequency waves, transferring energy from low to high frequency thermal oscillations. Even though nowadays we know the existence of many types of degeneration of internal waves, the increase of thermal oscillations with high frequency may strongly indicate the presence of higher horizontal baroclinic modes, high frequency internal waves.

Before we go any further in the analysis of group D, we need to discuss the meteorological conditions for internal wave generation in lakes and reservoirs. We analyzed the meteorological and the thermal stratification structure signals for each period, from group A to D. The comparison between the periods was based on results obtained previously considering regions with huge internal oscillations, group D, and small one, group B.

The daily average solar radiation is higher during the first days that precedes the analysis of October and November, Graph 6b. However, Group C presents a fall of the mean solar radiation during the days of analysis. The daily average solar radiation of group A and B is limited during the first days of analysis, indicating a lower thermal stratification of the reservoir. The high amount of solar radiation absorbed during group $\mathrm{D}$ was responsible to increase thermal stratification in this period, where internal wave activity was detected. This analysis reinforces the hypothesis that internal waves tend to be formed during summer, when the system is strongly stratified (MORTIMER, 1952).

Although solar radiation informs about the thermal stratification of closed basins, which in turn, provides clues about the excitation of internal waves, temperature variation within a stratified lake is not just correlated to the thermal stratification

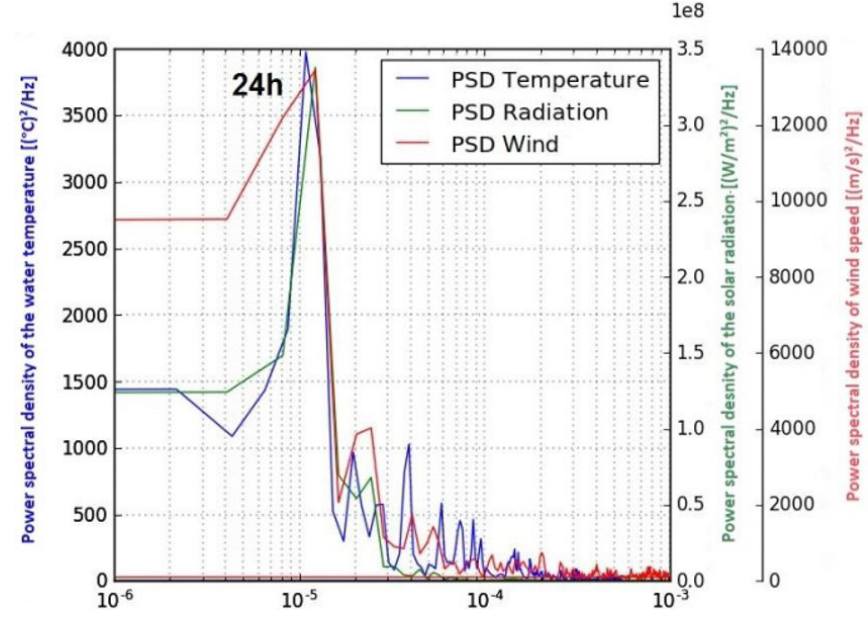

Graph 4. Power spectral density of the temperature and meteorological series for group C.

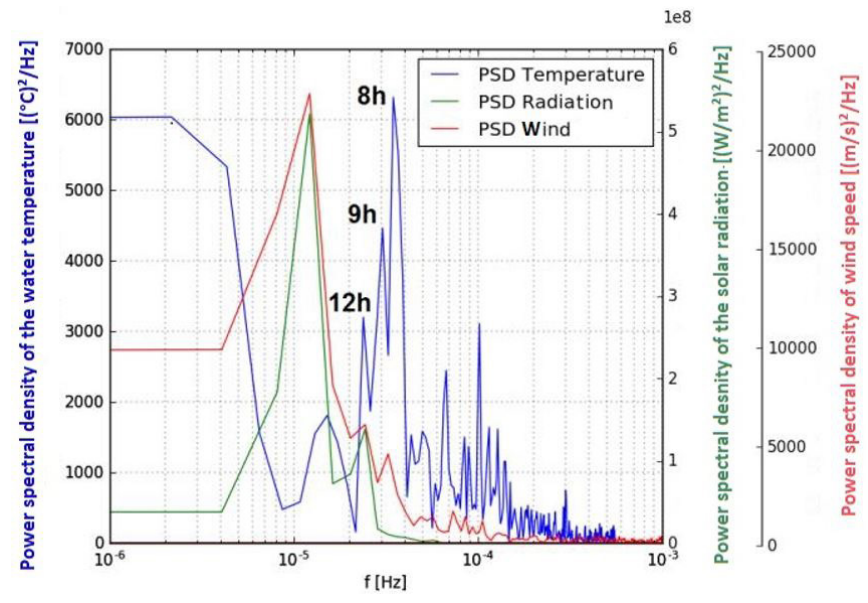

Graph 5. Power spectrum of the thermocline fluctuation for group D.
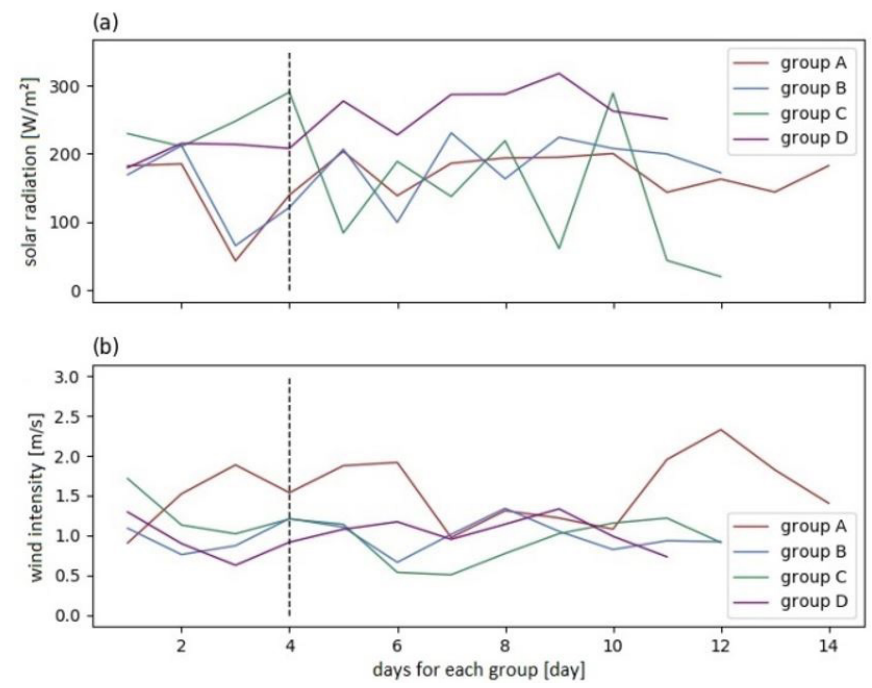

Graph 6. The mean daily variation of (a) solar radiation and (b) wind intensity in Vossoroca for groups A, B, C, and D. The black dashed line devided the analyzed period to last three days which precedes the analyzed period. 
frequency. The instability frequency, which normally is caused by wind events in reservoir and lakes, is another important variable that can define the probability for internal wave generation. As aforementioned, the wind increases the horizontal gradient pressure, and consequently is responsible to excite internal seiches. The daily mean wind events of $1.5 \mathrm{~m} / \mathrm{s}$ three days before the analyzed period (group D) was suitable to excite internal waves. Obviously weaker wind events may not be adequate to generate baroclinic motions. However, we did not identify periods with mean wind events lower than $1 \mathrm{~m} / \mathrm{s}$. As stated by Spigel and Imberger (1980), when the wind event is strong compared to the stratification, the system can be dominated by instabilities. In those cases, local mixing is more susceptible to occur. Thus, the combination between strong wind events and the low solar radiation intensity observed during day 1 to 3, Graph 6, did not allow the formation of internal waves in group $A$.

Group B also presented low solar radiation intensity during the first three days that precede the analyzed period. However, the low intensity of wind events excited higher frequency baroclinic modes. According to Sutherland (2010), internal waves have energy proportional to density gradient. Thus, since higher baroclinic modes carry lower energy, they can be generated by instability events with smaller intensity.

Group C did not generate internal waves even though strong wind events occurred and solar radiation, creating a great thermal stratified system. This occurred due to fact that although group $\mathrm{C}$ has presented intense wind events, the wind direction is not aligned to a main direction, Graph 7.

(a)

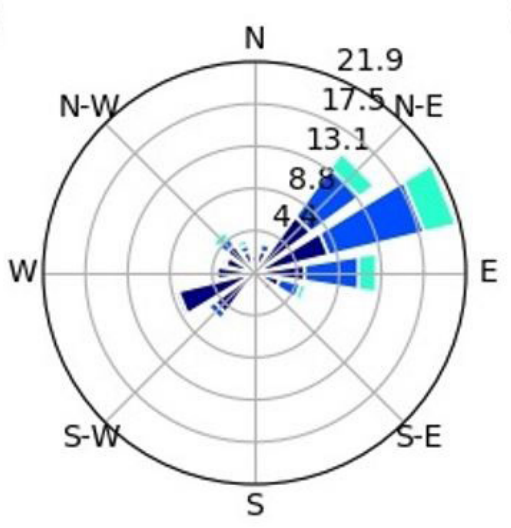

(c)

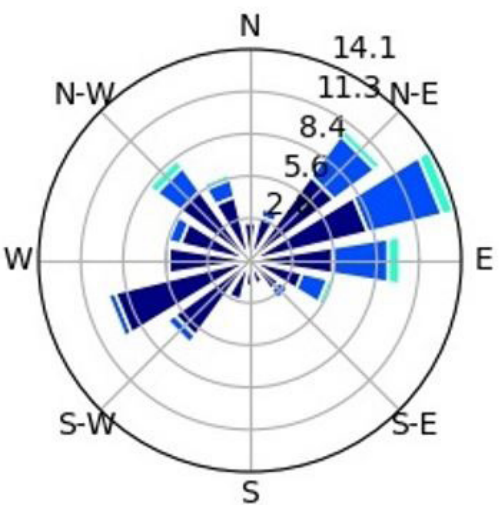

During the analyzed days of group $\mathrm{C}$ we did not observe a predominant wind direction. The wind direction changed abruptly for different directions. Thus, we concluded that even though the system presented meteorological condition to internal wave generation, the direction of the wind was not aligned to a predominant direction, reducing the force to displace the water for one basin shore, and consequently generate internal waves in the reservoir.

Although the mean daily wind events of $1.5 \mathrm{~m} / \mathrm{s}$ can be apparently weak to generate internal waves, the Vossoroca reservoir presents small length compared to literature. Bernhardt and Kirillin (2013) verified the occurrence of internal seiche in a lake of $3.2 \mathrm{~km}$ length excited by two days of constant wind event of $3 \mathrm{~m} / \mathrm{s}$. Thus, we can conclude that a wind event of $1.5 \mathrm{~m} / \mathrm{s}$ is acceptable to generate internal waves in Vossoroca reservoir, which has approximately $2.2 \mathrm{~km}$ length. Northeast wind events were responsible to excite internal waves in November, during a period of strong stratification and moderate wind events.

Since we have discussed the meteorological condition that excited internal waves in Vossoroca reservoir, now we can analyze in more detail group D data, the group showing three energetic peaks due to internal wave activity. As shown in Table 4, we firstly divided group D into three subgroups. The division was based on the spectral analysis of different periods of group D.

As we observed previously, many times the $24 \mathrm{~h}$ peak and its resonates observed in the water temperature spectrums is correlated to the variation of temperature due to the daily fluctuation of solar radiation. These peaks frequently are not (b)

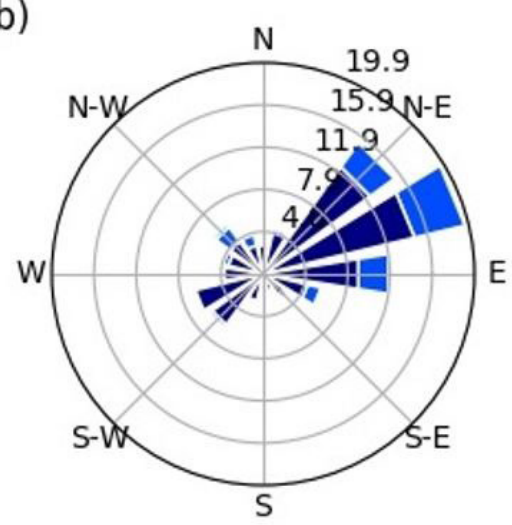

(d)

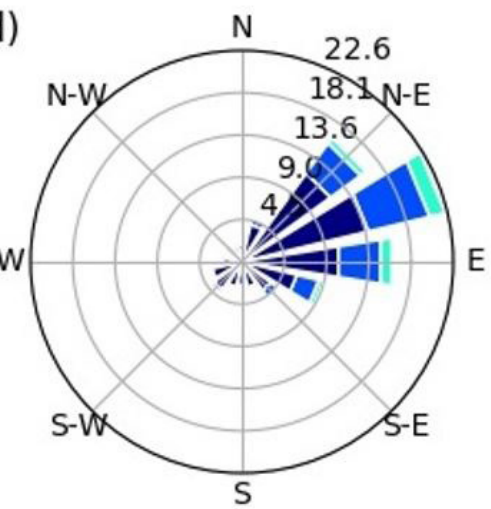

Graph 7. Wind rose of groups (a) A, (b) B, (c) C, and (d) D. 
Table 4. Subgroups of group D.

\begin{tabular}{cc}
\hline SUBGROUPS & PERIODS \\
\hline D1 & $16 / 11 / 2012-09 / 11 / 2012$ \\
D2 & $19 / 11 / 2012-21 / 11 / 2012$ \\
D3 & $21 / 11 / 2012-24 / 11 / 2012$ \\
\hline
\end{tabular}

caused by the internal wave passage. However, an internal wave with periodicity of $24 \mathrm{~h}$ can be hidden in the spectrum since we may consider these peaks as a simple time variation, and not physically wave. Thus, we must investigate the possibility that internal waves could be formed in frequencies that we already expect natural peaks. The theoretical period helps overcome this difficulty. Münnich, Wüest and Imboden et al. (1992) identified V2H1 internal waves in Lake Alpnach with periodicity of $24 \mathrm{~h}$. The identification was done through a model that estimated V2H1 waves with periodicity of $23 \mathrm{~h} 30$.

The 8 h peak $(\approx 7 \mathrm{~h} 56)$ observed in the spectrum of the thermal variation of the mean thermocline variation, Graph 8, presented high probability to be caused by internal wave activity.

We found fair agreement between the observed period (approximately $8 \mathrm{~h}$ ) and the calculated period $(7 \mathrm{~h} \pm 1 \mathrm{~h})$, Table 3 . According to the wave period, the excited baroclinic motion is classified as V1H1 mode, in which has wavelength $\lambda=4.4 \mathrm{~km}$, as presented in Table 2. Moreover, the solar radiation spectrum does not present energetic peaks in the period of $8 \mathrm{~h}$, strengthening the idea that the temperature oscillations are not due to solar radiation fluctuations. Frequently, adjacent peaks with lower energy are resonant peaks of the higher energy peaks. However, the $8 \mathrm{~h}$ period have more energy than the peaks of higher frequencies, which are responsible to the resonant peaks of meteorological variables.

In addition, another convincing sign that in this period we detect internal waves came from Polli (2014). She observed through Vossoroca reservoir field data that the turbulent diffusion coefficient was higher near the thermocline than the modeling value during the month of November 2012. The heat transfer model developed and applied by Polli (2014) in Vossoroca reservoir does not account the effect of baroclinic motions. Thus, internal wave action during the month of November could have increased the turbulent diffusion coefficient near the thermocline depth.

In the subgroup D2 we detected again multiple frequency peaks, Graph 9. The energetic peaks, detected between $19^{\text {th }}$ and $21^{\text {th }}$ day of November, is clearly due to baroclinic motions. As observed by Roget et al. (1997), it may suggest a superposition of baroclinic modes. Roget et al. (1997) identified in Banyoles Lake a superposition of V1H1 and V2H1 mode, with periodicity of $4 \mathrm{~h}$ and $7 \mathrm{~h}$, respectively. Through the spectral analysis we could identify that the $9 \mathrm{~h}$ oscillations are not significantly correlated to solar radiation peaks and the most energetic peaks of the period D2. Since the $9 \mathrm{~h}$ period does not match with the theoretical period of a fundamental baroclinic mode, Table 3, probably the internal wave excited does not have a V1 mode. In addition, another indication of the higher order is the lower wave energy observed for $9 \mathrm{~h}$ fluctuations compared to the $8 \mathrm{~h}$ periodicity, which was observed in subgroup D1. Thus, there are indications that this internal wave is a $\mathrm{V} 2 \mathrm{H} 1$ type.

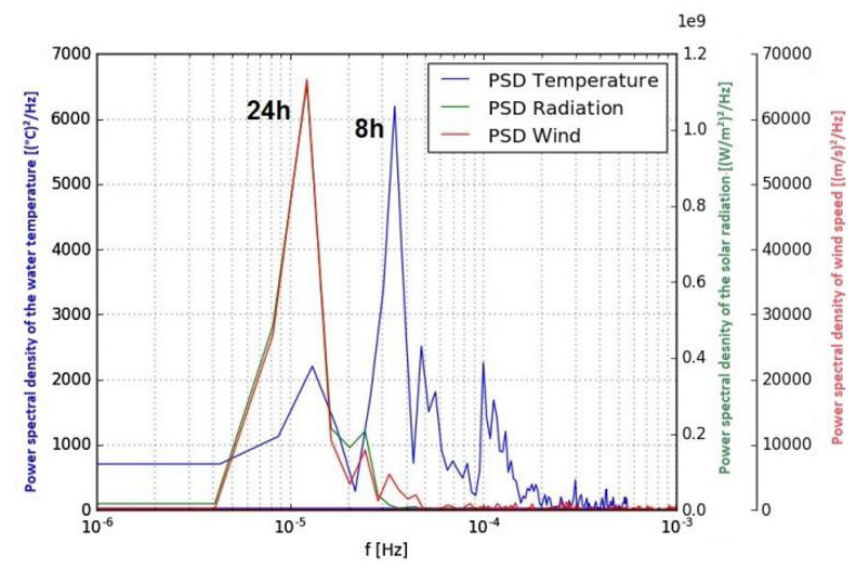

Graph 8. Power spectral density of the temperature and meteorological series for group D1.

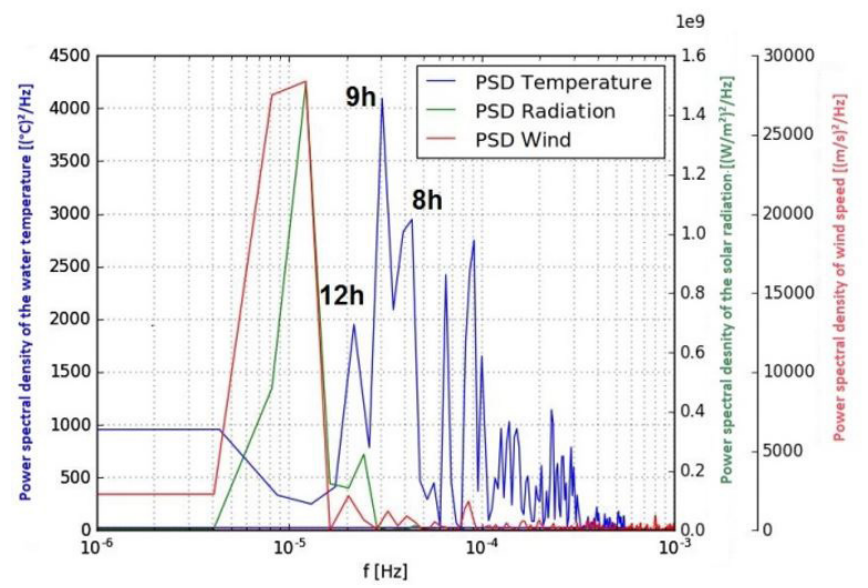

Graph 9. Power spectral density of the temperature and meteorological series for group D2.

The $12 \mathrm{~h}$ and $8 \mathrm{~h}$ peaks have lower energy than the $9 \mathrm{~h}$ peak. The $8 \mathrm{~h}$ oscillations only last for one day, the first one of the subgroup D2. However, it clear represents the same wave observed in subgroup D1, a V1H1 baroclinic wave. The $12 \mathrm{~h}$ periodicity also only last for one day, the last one of subgroup D2. This internal wave is the same wave that is observed in subgroup D3. Higher frequencies peaks, that are adjacent to the $8 \mathrm{~h}$ period, are resonant peaks of lower frequency oscillations. However, the considerable increase in energy of the high frequency spectrum can also indicate the degeneration of internal waves into nonlinear internal waves. According to Horn et al. (1998), V1H1 internal seiches can degenerate into packages of high frequency internal waves. Then, the V1H1 mode observed in subgroup D1 could be responsible to excite internal waves in the high frequency spectrum of subgroup D2, Graph 9.

The power spectral density of subgroup D3 shows a dominant and energetic peak of $12 \mathrm{~h}$ periodicity, Graph 10 . This peak was previously observed with lower energy in subgroup D2. However, Table 3 shows that the theoretical period for a V1H1 baroclinic mode does not match with this peak. 


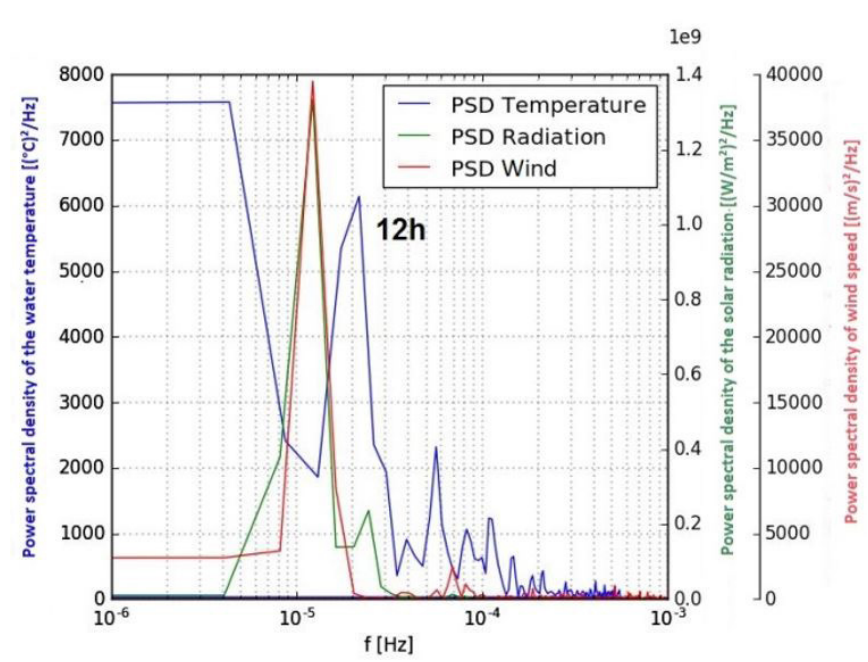

Graph 10. Power spectral density of water temperature and meteorological data D3.

A high periodicity compared to internal waves excited in subgroup D1 and an epilimnion with more thermal variations than observed in subgroups D1 and D2 indicate that the $12 \mathrm{~h}$ periodicity is due to the excitation of higher vertical baroclinic waves.

Finally, we obtained the power spectrum of the thermocline depth series to examine and estimate the local amplitude of internal waves formed during group D. Thus, we obtained that internal waves generated during period D with periodicity of $9 \mathrm{~h}, 12$, and $8 \mathrm{~h}$ had initial amplitude of 45, 47, and 55 centimeters, respectively (Graph 11).

The thermal variation due to the passage of the $8 \mathrm{~h}$ internal wave can be identified easily through the temporal variation of the water column temperature, Graph 12. The V1H1 baroclinic waves identified in subgroup D1 can be clearly observed on November 16 near the thermocline depth. From day 17, the thermal variations increased in frequency content, difficulting the detection of variations with different periodicities.

The rise of thermal variation, observed after the first day of subgroup D2, could be due to the degeneration of V1H1 internal wave of $8 \mathrm{~h}$ periodicity. This increase of variation was also observed through the water temperature spectrum for subgroup D2, Graph 9.

Although the internal waves generated with periods of $9 \mathrm{~h}$ and $12 \mathrm{~h}$ are complicated to be detected through

Graph 12, the amplitude reduction of the thermal variation after 19 November is clearly perceptible. This corroborates with the hypothesis that the internal seiches formed in subgroups D2 and D3 are higher order waves, probably a V2H1. Thus, the energy is not concentrated near the thermocline. In addition, another point that justifies the generation of high vertical modes is the epilimnion structure. The epilimnion became less homogenous and presented a continuous stratification. As we can observe, after day 19 the thermal stratification increased. Although the thermal stratification increased, the metalimnion thickness did not present a size reduction. However, we detected a continuous rise of the water density at the metalimnion end.

Even though we have detected apparently small amplitude waves in Vossoroca reservoir, with maximum amplitude of $55 \mathrm{~cm}$, the total variation is approximately of 1 meter. In addition, the

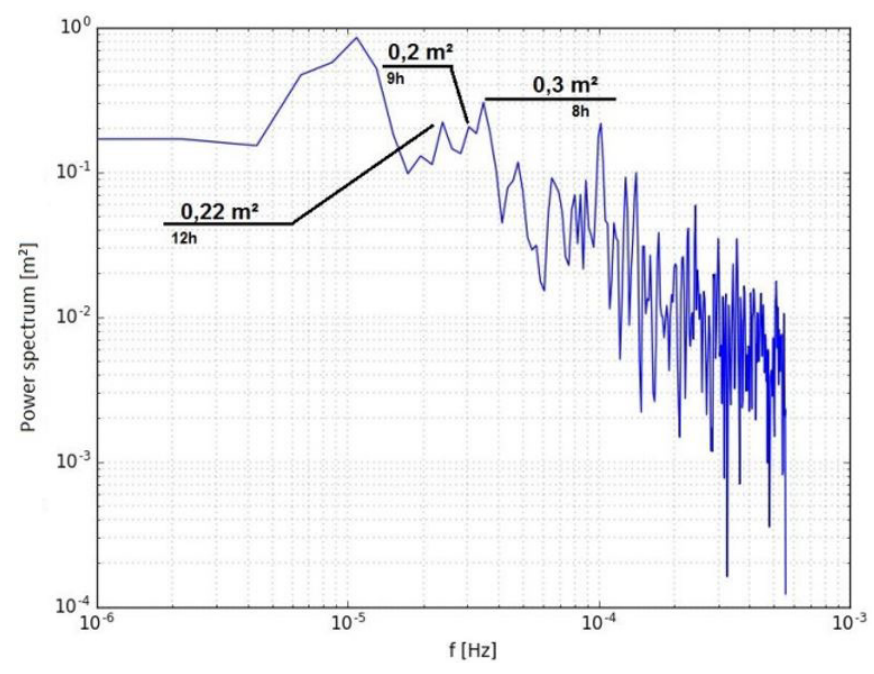

Graph 11. Power spectrum of the thermocline fluctuation for group D.

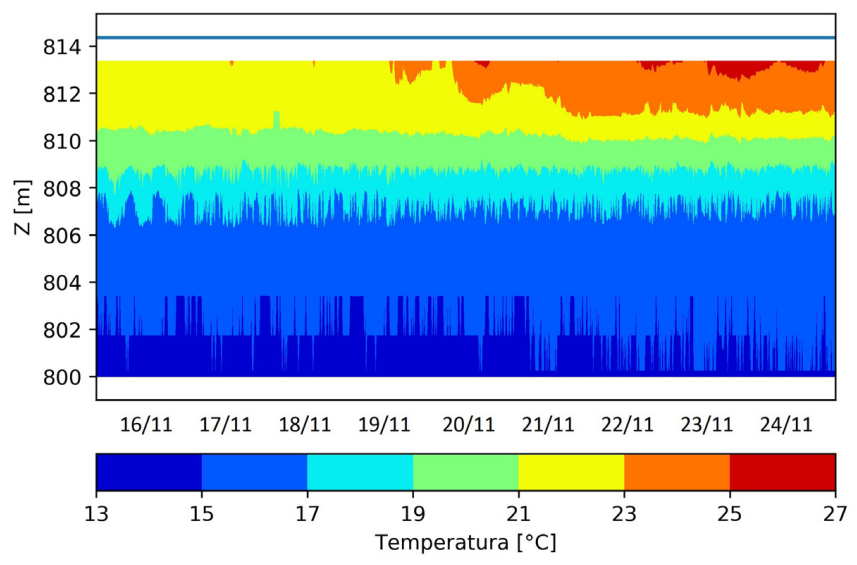

Graph 12. Measured temporal variation of temperature over the water column.

ecological and physical effects of these waves are not limited to the thermocline depth. As we could see, the wave energy can concentrate in different depths of the system. Thus, we can conclude that large internal seiches can be generated even in a dendritic reservoir. As observed by Polli (2014), this thermal fluctuation increases the turbulent diffusion coefficient, and consequently it was responsible to rise mixing during the month of November 2012. Mannich (2013) also highlighted the importance of internal waves. According to him, internal waves can increase the methane emission in Vossoroca reservoir. Thus, more studies can be done to explore the effect of these waves, seeking to quantify the effects in chemical compounds, nutrients, and microorganism fluxes due to the internal waves action.

\section{CONCLUSION}

In this research we developed an algorithm to identify internal waves in Vossoroca reservoir. For validation, we used measured water column temperature and meteorological measurements, such as solar radiation and wind intensity and direction. The Vossoroca 
reservoir has an area of 330 ha and a dendritic shape, unusual characteristics for an internal waves investigation. We analyzed the power spectral densities and the power spectrum of the thermal variations of the mean thermocline depth. Both spectral analyses are derived from the Fourier transforms. The choice of periods was based on data quality and Brunt-vaisala frequency.

We obtained data from the second semester of 2012. We did not identify any internal wave activity during periods of strong wind events and low solar radiation, which characterize a system with soft stratification and susceptible to mixing. When the system was not completely stratified, but was disturbed by weak wind events, higher vertical baroclinic waves were excited. However, since higher modes do not concentrate energy at thermocline depth and the wind intensity was limited during this period, the system excited internal seiches with low energy. Between 10 and 19 September, the thermal variation in the mean thermocline depth was lower than $15 \mathrm{~cm}$.

As a result of the solar radiation increase and wind events of $1.5 \mathrm{~m} / \mathrm{s}$ pointed out for the northeast direction, V1H1 and V2H1 internal seiches were excited from 16 to 24 November. Frequency spectrums identified the occurrence of a V1H1 internal baroclinic mode with $8 \mathrm{~h}$ periodicity and amplitude of $0.55 \mathrm{~m}$ between 16 and 19 November. These thermal variations were clearly detected through the isotherm analysis during these days and even more during 16 November. The internal waves detected during the 6 last days were not well visible in the water temperature profile series. The reason is that many undefined frequencies were observed. One of the hypotheses is that the $8 \mathrm{~h} \mathrm{V1H1}$ internal wave seiche could be degenerated into high frequency waves.

Even though it is hard to detect the $9 \mathrm{~h}$ and $12 \mathrm{~h}$ periodicity, the thermal oscillations decreased after the passage of the $8 \mathrm{~h}$ internal wave. However, although we had observed the energy reduction, we detected the $9 \mathrm{~h}$ and $12 \mathrm{~h}$ wave through the spectral analysis of the thermal variation near the thermocline. Since the temperature fluctuations in this period were small, the theoretical value was lower than the value obtained in the spectral analysis and the system presented a continuum thermal stratification of the hypolimnion and metalimnion. Thus, these waves were classified as baroclinic waves of higher vertical modes.

These internal waves were found between 20 and 24 November. The $12 \mathrm{~h}$ and $9 \mathrm{~h}$ fluctuations had amplitude of $0.47 \mathrm{~m}$ and $0.45 \mathrm{~m}$, respectively. According to the vertical wave pattern, these baroclinic motions did not occur near the thermocline. However, all internal seiche formed in November contributed to increase the turbulent diffusion coefficient and show why probably the 1D thermal model developed by Polli (2014) presented a higher error in November.

Overall, the identification of internal seiches during the month of November agreed well with the internal waves theory, which indicates that the probability of internal waves is higher during the summer, period of highest density stratification. Thus, future studies can extend the period of analysis to investigate the internal wave activity in Vossoroca reservoir during months of December and January, period of high thermal stratification. Future researches can be benefit from the fact that long internal waves, V1H1 baroclinic mode, can also be generated in dendritic basins.

The developed algorithm was based on internal waves analysis for Vossoroca reservoir, however, can be easily used for other closed water basins. The two-layer model can be modified for different basin sizes, since the flow is not affected significantly by the Coriolis force and the system does not have a rugged topography. The model developed has many simplifications, not just neglecting the nonlinear terms, but also assuming that just fundamental baroclinic waves, V1H1 mode, are generated. Thus, the analytical model used is not applicable to predict higher frequency internal waves and higher vertical baroclinic modes. The two-layer model used in this study also neglects the degeneration of long internal seiches. Nevertheless, this study satisfactorily identified V1H1 internal waves activity and gave an indication of the degeneration of long internal wave in dendritic water basins. However, the effect on quarter quality caused by internal waves was not investigated. Future studies can explore and investigate the effects in chemical compounds, nutrients, and microorganism fluxes due to internal wave action, comparing period with internal wave activity and periods without the excitation. Future researches can also explore the degeneration of internal waves and the internal wave patterns considering higher baroclinic modes excitation in dendritic thermal stratified water basins. In addition, this study provides motivation for further internal wave investigation in Brazilian lakes and reservoirs since the hydrodynamic of stratified system is many time ignored.

\section{ACKNOWLEDGEMENTS}

The authors thank the Coordination of Improvement of Higher Education Personnel (CAPES) and the Nationcal Council for Scientific and Technological Development (CNPq) for all financial support. We also would like to thank Dr. Michael Mannich, MSc. Julio Werner and MSc. Artur Braga for providing the thermistor chain and meteorological data and for all support given in this research. We are gratefull to COPEL (Companhia Paranaense de Energia) for allowing access to the Vossoroca reservoir and private facilities.

\section{REFERENCES}

ANTENUCCI, J. P.; IMBERGER, J.; SAGGIO, A. Seasonal evolution of the basin-scale internal wave field in a large stratified lake. Limnology and Oceanography, v. 45, n. 7, p. 1621-1638, 2000. http://dx.doi.org/10.4319/lo.2000.45.7.1621.

BENGTSSON, L.; HERSCHY, R. W. Encyclopedia of lakes and reservoirs. Monographiae Biologicae, v. 53, p. 10-26, 2012.

BERNHARDT, J.; KIRILLIN, G. Seasonal pattern of rotationaffected internal seiches in a small temperate lake. Limnology and Oceanography, v. 58, n. 4, p. 1344-1360, 2013. http://dx.doi. org/10.4319/lo.2013.58.4.1344.

DENNY, M. W.; GAINES, S. D. Encyclopedia of tidepools and rocky shores. Berkeley: University of California Press, 2007.

DOWNING, J. A.; PRAIRIE, Y. T.; COLE, J. J.; DUARTE, C. M.; TRANVIK, L. J.; STRIEGL, R. G.; MCDOWELL, W. H.; KORTELAINEN, P.; CARACO, N. F.; MELACK, J. M.; 
MIDDELBURG, J. J. The global abundance and size distribution of lakes, ponds, and impoundments. Limnology and Oceanography, v. 51, n. 5, p. 2388-2397, 2006. http://dx.doi.org/10.4319/ lo.2006.51.5.2388.

FOFONOFF, N. P.; MILLARD, R. C. (Ed.). Algorithms for computation of fundamental properties of seawater. Paris: UNESCO, 1983. (UNESCO Technical Papers in Marine Sciences, 44).

HAVELOCK, D.; KUWANO, S.; VORLÄNDER, M. (Ed.). Handbook of signalprocessing in acoustics. New York: Springer Science \& Business Media, 2008. http://dx.doi.org/10.1007/978-0-38730441-0.

HEIZEL, G.; RUDIGER, A. (Ed.). Spectrum and spectral density estimation by the Discrete Fourier Transform (DFT), including a comprehensive list of window functions and some new at-top windows. Germany: AlbertEinstein Institut: Hannover, 2002. 54 p.

HORN, D.; IMBERGER, J.; IVEY, G. The degeneration of basin-scale internal waves in lakes. In: AUSTRALASIAN FLUID MECHANICS CONFERENCE, 13., 1998, Melbourne. Proceedings... Nedlands: The University of Western Australia, 1998. p. 863-866.

HUT'TER, K.; WANG, Y.; CHUBARENKO, I. P. (Ed.). Physics of lakes. Volume 2: lakes as oscillators Advances in geophysical and environmental mechanics and mathematics. Heidelberg: Springer, 2011.

KODAIRA, T.; WASEDA, T.; MIYATA, M.; CHOI, W. Internal solitary waves in a two-fluid system with a free surface. Journal of Fluid Mechanics, v. 804, p. 201-223, 2016. http://dx.doi.org/10.1017/ jfm.2016.510.

LAZERTE, B. D. The dominating higher order vertical modes of the internal seiche in a small lake. Limnology and Oceanography, v. 25, n. 5 , p. $846-854,1980$.

LEMMIN, U.; MORTIMER, C. H.; BÄUERLE, E. Internal seiche dynamics in Lake Geneva. Limnology and Oceanography, v. 50, n. 1, p. 207-216, 2005. http://dx.doi.org/10.4319/lo.2005.50.1.0207.

LIKENS, G. E. (Ed.). Lake ecosystem ecology: a global perspective. Millbrook: Academic Press, 2010.

MANNICH, M. Estimativa de emissões de gases do efeito estufa em reservatórios e lagos. 2013. Tese (Doutorado em Recursos Hídricos e Ambiental) - Programa de Pós graduação em Recursos Hídricos e Ambiental, Universidade Federal do Paraná, Curitiba, 2013.

MORTIMER, C. H. Water movements in lakes during summer stratification; evidence from the distribution of temperature in Windermere. Philosophical Transactions of the Royal Society of London. Series B, Biological Sciences, v. 236, n. 635, p. 355-398, 1952. http:// dx.doi.org/10.1098/rstb.1952.0005.

MORTIMER, C. H. (Ed.). Large scale oscillatory motions and seasonal temperature changes in Lake Michigan and Lake Ontario. Milwaukee:
University of Wisconsin Press, 1971. (Center Great Lakes Studies. Special reports, 12).

MORTIMER, C. H. (Ed.). Lake Michigan in motion: responses of an inland sea to weather, earth-spin, and human activities. Milwaukee: The University of Wisconsin Press, 2004.

MÜNNICH, M.; WÜEST, A.; IMBODEN, D. M. Observations of the second vertical mode of the internal seiche in an alpine lake. Limnology and Oceanography, v. 37, n. 8, p. 1705-1719, 1992. http://dx.doi.org/10.4319/lo.1992.37.8.1705.

PANNARD, A.; BEISNER, B. E.; BIRD, D. F.; BRAUN, J.; PLANAS, D.; BORMANS, M. Recurrent internal waves in a small lake: Potential ecological consequences for metalimnetic phytoplankton populations. Limnology and Oceanography: Fluids and Environments, v. 1, n. 1, p. 91-109, 2011.

PAPANDREOU-SUPPAPPOLA, A. (Ed.). Applications in timefrequency signal processing. Florida: CRC Press, 2002. http://dx.doi. org/10.1201/9781420042467.

POLLI, B. A. (Ed.). Modelagem 1D do fuxo vertical de calor em corpos de água horizontalmente homogêneos. 2014. Dissertação (Mestrado em Recursos hídricos e ambiental) - Programa de Pós graduação em Recursos Hídricos e Ambiental, Universidade Federal do Paraná, Curitiba, 2014.

READ, J. S.; HAMILTON, D. P.; JONES, I. D.; MURAOKA, K.; WINSLOW, L. A.; KROISS, R.; WU, C. H.; GAISER, E. Derivation of lake mixing and stratification indices from high-resolution lake buoy data. Environmental Modelling \& Software, v. 26, n. 11, p. 13261327, 2011. http://dx.doi.org/10.1016/j.envsoft.2011.05.006.

ROGET, E.; KHIMCHENKO, E.; FORCAT, F.; ZAVIALOV, P. The internal seiche field in the changing South Aral Sea (20062013). Hydrology and Earth System Sciences, v. 21, n. 2, p. 1093-1105, 2017. http://dx.doi.org/10.5194/hess-21-1093-2017.

ROGET, E.; SALVADÉ, G.; ZAMBONI, F. Internal seiche climatology in a small lake where transversal and second vertical modes are usually observed. Limnology and Oceanography, v. 42, n. 4, p. 663-673, 1997. http://dx.doi.org/10.4319/lo.1997.42.4.0663.

SAGGIO, A.; IMBERGER, J. Internal wave weather in a stratified lake. Limnology and Oceanography, v. 43, n. 8, p. 1780-1795, 1998. http://dx.doi.org/10.4319/lo.1998.43.8.1780.

SCIPY. Interpolate a 1-d function. 2014. Available from: <https:// docs.scipy.org/doc/scipy/reference/generated/scipy.interpolate. interp1d.html>. Access on: 17 jan. 2017.

SCIPY. Remove linear trend. 2016. Available from: < https://docs. scipy.org/doc/scipy/reference/generated/scipy.signal.detrend. html>. Access on: 17 jan. 2017.

SIMMONS, H.; CHANG, M. H.; CHANG, Y. T.; CHAO, S. Y.; FRINGER, O.; JACKSON, C. R.; KO, D. S. Modeling and prediction 
of internal waves in the South China Sea. Oceanography, v. 24, n. 4, p. 88-99, 2011. http://dx.doi.org/10.5670/oceanog.2011.97.

SOCOLOFSKY, S. A.; JIRKA, G. H. (Ed.). Special topics in mixing and transport processes in the environment. engineering: lectures. 5th ed. College Stayion: Coastal and Ocean Engineering Division, Texas A\&M University, 2005.

SPIGEL, R. H.; IMBERGER, J. The classification of mixed-layer dynamics of lakes of small to medium size. Journal of Physical Oceanography, v. 10, n. 7, p. 1104-1121, 1980. http://dx.doi. org/10.1175/1520-0485(1980)010<1104:TCOMLD>2.0.CO;2.

STRASKRABA, M.; TUNDISI, J. G.; DUNCAN, A. (Ed.). Comparative reservoir limnology and water quality management. Heidelberg: Springer Science \& Business Media, 2013.

SUTHERLAND, B. R. (Ed.). Internal gravity waves. New York: Cambridge University Press, 2010. http://dx.doi.org/10.1017/ CBO9780511780318.

WATSON, E. R. Internal oscillation in the waters of Loch Ness. Nature, v. 69, n. 1782, p. 174, 1903. http://dx.doi.org/10.1038/069174a0.
WATSON, E. R. Movements of the waters of Loch Ness, as indicated by temperature observations. The Geographical Journal, v. 24, n. 4, p. 430-437, 1904. http://dx.doi.org/10.2307/1775951.

WERNER, J. Interpretation and applicability of local residence time in reservoirs. 2013. Dissertação (Mestrado em Recursos hídricos e ambiental) - Universidade Federal do Paraná, Curitiba, 2013.

WETZEL, R. G. (Ed.). Limnology: lake and river ecosystems. Houston: Gulf Professional Publishing, 2001.

WILDERER, P. A. (Ed.). Treatise on water science: four-volume set. Elsevier Science: Amsterdam, 2010.

\section{Authors contributions}

Rafael de Carvalho Bueno: Literature review, data processing, analysis and discussion of results and writing of the article.

Tobias Bernward Bleninger: Advisor, discussion of results and final paper review. 